\title{
Minimal Materials for ESL Beginners
}

\author{
N. S. Prabhu \\ doi:10.7575/aiac.alls.v.1n.1p.81
}

In November 2006, the government of the state of Karnataka in India announced its decision to start teaching English as a school subject from class 1 onwards in all primary schools in the state, instead of from class 5 as hitherto.

There are upwards of 40,000 primary schools in the state. No teacher taught English to any class lower than 5 in the past 40 years. Teaching English in class 1 was now to begin in the academic year commencing in June, 2007 - seven months from the government's decision. Further, English was to be taught from that time (June, 2007) not only to class 1 but to classes 2, 3 and 4 as well, which would all be beginning to learn it.

The government's decision was in response to a situation of public protest and growing unpopularity resulting from its refusal to allow any English-medium instruction in schools in the state: it was now seeking to soften its anti-English image by increasing the teaching of English as a subject (as distinct from the medium of instruction).

For educators, however, this presented a task that could well be called impossible - academically, logistically, time-wise, resource-wise, etc. 
It led them to ask what was minimally and most essentially needed and how that could be managed by teachers drawing on their normal abilities as adults, language users, parents, etc, rather than as trained teachers putting their training to use.

Briefly, they decided that teachers should use five types of activity in the classroom:

1. Telling the children a story in English (perhaps 10 minutes)

2. Reciting / repeating / chorusing a rhyme / song in English (5 minutes)

3. Interpreting and carrying out commands in English - what has been called Total Physical Response (Asher) or the Inperative Drill (Palmer) (8 minutes)

4. Repeating / enacting short dialogues in English - five or six exchanges in each, relating to personal, social or occupational contexts, such as making someone's acquaintance, asking about the way, getting information from someone, making a complaint, showing appreciation, etc. (8 minutes)

5. Engaging in a game or activity, usually in a group, which may involve finding something in a picture or making a connection between things or rearranging things using one's own (or given) logic or deciding on / carrying out a colouring scheme for a picture, etc. (8 minutes)

Essentially, we wanted pupils to be doing one or another of three things: 
- Experiencing the language - by having to / managing to make sense of the language encountered - hence, stories and total physical response

- Repeating and retaining in the mind a set of texts / samples of use of the language, to constitute a form of learner's corpus - hence, rhymes and dialogues

- Attempting, individually or in a group, to get to a given goal using what is available - hence the activity.

It wasn't envisaged that each lesson would have all five (or any fixed number of) activities: that was very likely to vary from one classroom to another or one day to another. We would ask teachers to treat story-telling as a necessary part of each lesson and to use the rest of the lesson for any two or three (when possible all four) activities -- ensuring, however, that the same kind of activity was not repeatedly left out.

Two crucial points were agreed on within the group designing the programme and with the state government. First, there would only be oral activity in the classroom in the first year and in much of the second year, with the alphabet being introduced in the second, and reading only in the third. The group, which had in mind the educational arguments that formed the basis of the Oral Method a century ago, were warned that this would be unacceptable to parents / the public who maintained deep associations between schooling and literacy (and between a language and its written form). We hoped, however, to win people over with the argument that since children are taught the alphabet of their mother tongue in class 1 , it would be an unreasonable burden on them - and quite possibly a hurdle 
in acquiring mother-tongue literacy - to have to cope with literacy in English as well. Secondly, there would be no examinations / promotion tests in English in the first four years. The group proposed this in view of the impracticability of conducting oral tests in the first two years, as well as the unknown problems of teaching essentially the same thing to classes 1 to 4 (all beginners) and yet trying to achieve some grading from lower to higher classes. The government accepted it probably to avoid the risk of public protest in the event of large numbers of failures.

To create the teaching materials needed, five small groups (6 to 8 members) were set up, consisting of primary school teachers known to be specially able and interested or teachers already in a leadership role as staff of Teachers' Centres or Training Schools. They were drawn from their working places in different parts of the state (often separated by hundreds of miles) and asked to work together in Bangalore over five days, each group identifying / compiling / devising one of five kinds of material: (i) a collection of stories likely to be of interest to 5-yearolds and not too difficult for a teacher to put across (with the help of pictures, gestures, miming, words in the mother-tongue, as needed), (ii) a collection of rhymes in English - short, likely to be comprehensible to children (at least roughly and with help in the form of miming, etc, from teachers) and recitable with a rhythm (whether or not a teacher is able to sing them), (iii) a set of commands for pupils to listen to, guess the meanings of and carry out, sufficient to serve as samples for teachers to think up / put together further sets of commands on their own, (iv) a collection of short, 'functional' dialogues placed in contexts likely to be familiar / easily conceivable and couched in common, 
stereotypical phrases which can be easily borrowed in other such interactions, and (v) a collection of group games / activities likely to be engaging and manageable for pupils. This five-day workshop was repeated a couple of weeks later, to enable the groups to complete what they felt was incomplete and to go over / improve the work done. The outcome was a collection of about 80 stories, 100 rhymes, 40 sets of TPR commands, 60 dialogues and 30 types of activity. Since the academic year in a primary school consists of about 130 days and the education department was allotting a lesson a day to English, we needed material for 130 lessons. Given that some of the stories would need to be retold, at pupils' request or for fuller comprehension, and that the other four kinds of activity would be used not in all but only in a majority of the lessons, we reckoned that what the groups had produced was enough for a year's teaching.

These materials were all printed in a teachers' resource book, to be made available to all teachers. The rhymes, dialogues and TPR commands were in the language and form in which they could be presented to the class, though they were not meant to be used in the sequence in which they appeared in the book. Teachers were to be asked to re-sequence them freely by asking themselves regularly (every couple of days) how well the rhymes, dialogues or sets of commands used in the last day or two had gone and which of the remaining ones might be best used. Next, they were also to be encouraged to use any rhymes they might know themselves and consider suitable, and to make up further sets of TPR commands by combining existing ones differently or adding some new ones. 
The stories, however, were different. Though they were simplified in a general way where the language seemed too advanced, there was no attempt to put them in the form of texts suitable for presentation to pupils. It was left to each teacher to put them in language judged by her to be comprehensible to her class - and to reword them or support them with gestures/actions - in the light of actual evidence as they were being told. Each teacher was thus given the challenge and responsibility of enabling the class to understand a story told in English. Further, the resource book did not sequence the stories in any graded or recommended order; each teacher was to decide each day on the story to be told the next day, guided by the evidence of success seen with the story told earlier that day / the previous day / the last few days. Further, a teacher did not always have to choose a story from the resource book; she was free (in fact, encouraged) to use some story from her own memory / experience if so prompted by her observation of the last (or a recent) lesson. In story-telling, therefore, the teacher was to use her own resources in English, together with what resourcefulness she could muster in conveying things to the young, thus employing the skills available to a parent or adult language user in attempting to communicate with a child or someone with much less knowledge of the language, rather than drawing on some knowledge or skill available to her as a trained teacher, or relying on what has been judged to be suitable and prepared in advance by others.

While the resource book would thus be a support to each teacher in choosing and planning each day's lesson, there would be no book for pupils to possess and use until we were ready to introduce the alphabet to them - perhaps towards the end of the second year. We were told, however, that many pupils would feel deprived 
of an essential part of schooling if they didn't use a book - and that many more parents would feel so much more strongly. Meanwhile, we were aware that children liked to have a picture to look at while they are listening to a story. So it was decided to have a book for pupils containing pictures related to the different stories in the resource book, so that the teacher could refer the class to the picture(s) on a certain page before starting to tell them one of those stories. Given such a pupil's book, it was decided to use the pictures in it for many of the activities too -- e.g., colouring, completion - and to include in it some figures / diagrams specially for use in such activities. Further, some of the activities could now be set as homework, thus bringing the pupil's book into use at home.

There is a network of teachers' centres in the state, all linked up by satellite television. They are so spaced out that no school -- Primary or Secondary-- is farther than about a hundred kilometres from one of them. This means that large numbers of teachers in all parts of the state can assemble at the different centres at a given time and receive an audio-visual programme put out from one central place (or one of two central places) in the state. Further, the audio link is two-way between the source of the programme and the receiving centres, making it possible to have question-and-answer sessions between those who are putting out the programme and those who are receiving it, at any stage of the proceedings. This facility is used by the Education Department of the state at various times in the year - normally on days fixed in advance and built into the academic calendar - for updating or orientating the relevant teachers (those who teach certain classes; those who teach certain subjects) as needed. 
This facility was now used to do an orientation of all those Primary School teachers who were going to teach English using the source materials prepared for the purpose. First, the source materials themselves were printed and sent out to all the relevant schools, such that every teacher concerned had a copy. Then certain days were fixed for teachers to assemble at the centres and take part in the orientation programme. Various members of the groups which had been involved in designing the new curriculum or putting together the source materials were sent to different teachers' centres to be on hand to answer teachers' queries and to monitor their response while they were receiving the programme. The programme was broadcast over about five hours each day, consisting of a brief description of the curriculum and the five kinds of pedagogic activity along with an indication of their rationale, and advice on planning and carrying them out using the help available in the source book. Teachers were in particular told not to read the stories aloud to the class but, instead, to tell them in their own words such that they would be understood, not to try to explain the words / lines of rhymes, other than to 'act' things out while reciting them, and not to worry about the tune or pitch of a rhyme as long as the rhythm was maintained in the recitation.

Teaching the new course started in June / July, 2007 and there seemed to no major problems (or protests ) in the first few months, other than some bewilderment / unhappiness that the alphabet was not being taught and that no language / text was to be explained / explicated to pupils. This was reassuring though it did not constitute any positive evidence. For us even an indication that most teachers were carrying out most of the classroom activities in the way intended would not have been sufficiently positive feedback. This was because the course did not 
consist of a body of specific inputs which, if 'put into' the learner, would constitute or result in learning ; it consisted, rather, of a set of formats for classroom interaction between teachers and learners, with just some initial 'props' for practising them for a while. We were hoping that in the course of attempting to tell various stories to a class, the teacher would begin to develop a feel for stories that were more likely to succeed than others or for ways of telling that would be more successful than others; and this would also entail being more and more able to see when the telling of a story has been specially successful / rewarding / pleasurable - or will probably prove to be so. This would mark the beginning of pedagogic judgement in the teacher arising from ongoing classroom experience teacher development in the truest sense, as we saw it. Once it begins, such judgement (or 'feel' or 'intuition') tends to play a part in how the teacher feels about further classroom activity in future teaching and tends to firm up and develop the judgement itself further. In this way the teacher will be able to modify the collection of stories she started with, putting together a collection of her own for use in the next year's teaching - in effect, developing and refining a curriculum of her own year after year. One can hope for the same kind of process to happen with the rhymes, TPR commands, dialogues and games. Any indication that something like this was happening - even in a faint or uncertain form - would have counted as valuable positive evidence.

But the political party that was in power in the state when the course was introduced broke up some three months after the teaching started and there were several months of political uncertainty followed by an election and a new government with a new minister in charge of primary education. When power 
shifts from one political party to another, the new party in power has a habit of reversing some decisions of its predecessor, especially those that are seen as risky or controversial, and educational innovation is a frequent candidate for this treatment. There has, as a result, been no official initiative or support (or reason to expect sympathy) for any follow-up action or study over the past year- there have, indeed, been occasional statements or intimations to the media tending to give a negative view, for instance, that teachers and learners need to have proper books to learn from or that there is now a need do a large-scale revision of the curriculum, from class 1 onwards. Unofficial and partial information from schools points to an adaptation to more traditional procedures, such as reading the stories aloud with an explication of the text, and also something like a ritualisation of rhymes, dialogues and TPR. 